\title{
ZERO-GRADIENT ROTATIONAL DIFFUSION CONSTANTS OF SOME POLYDISPERSE CLAY MINERAL SOLS
}

\author{
by \\ W. T. Granquist* and C. A. Hollingsworth \\ Department of Chemistry, University of Pittsburgh, Pittsburgh 13, Pa.
}

\begin{abstract}
Rotational diffusion constants were determined as a function of shear gradient in a region of low shear (generally, less than $20 \mathrm{sec}^{-1}$ ) for various concentrations (generally, less than 0.1 per cent clay by weight) of polydisperse aqueous dispersions of montmorillonite, hectorite, and attapulgite. Extrapolation of these data to zero shear gave concentration dependent zero-gradient rotational diffusion constants. Proper treatment of these results permitted a linear extrapolation to zero concentration to give $\theta_{\mathrm{G}=0, \mathrm{c}=0}$, the zero-gradient zero-concentration rotational diffusion constant, for each of the clay systems.

Particle size distributions were determined for each of the clays by a direct eounting technique, based on electron micrographs prepared from dilute $(\sim 0.005$ per cent clay dispersions. These distributions were then used to calculate a $\theta_{\mathrm{G}=0, \mathrm{C}=\mathrm{a}}$ for each system, on the basis of the relationship

$$
\theta_{\mathrm{G}=0, \mathrm{C}=0}=\frac{\sum \phi_{i} / \theta_{i}}{\sum_{i} \phi_{i} / \theta_{i}^{2}},
$$

where $\theta_{i}$ is the rotational diffusion constant and $\phi_{i}$ is the volume fraction of the $i$ th monodisperse component of the polydisperse system.

Agreement between the calculated and experimental values of $\theta_{\mathrm{G}=0, \mathrm{C}=0}$ was good. Thus, theoretical and experimental considerations both lead to the conclusion that the behavior at low shear of polydisperse systems, such as these, is governed by the relatively few large particles in the distribution.
\end{abstract}

* National Lead Fellow, Mellon Institute, Pittsburgh 13, Pa. 